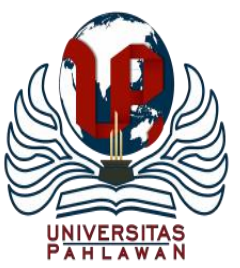

Edukatif : Jurnal Ilmu Pendidikan Volume 2 Nomor 2 Tahun 2020 Halm 210-214

EDUKATIF: JURNAL ILMU PENDIDIKAN

\author{
Research \& Learning in Education \\ https://edukatif.org/index.php/edukatif/index
}

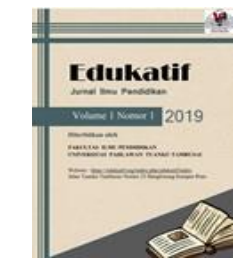

\title{
Metode Kooperatif Tipe Stad Dan Problem Posing Dalam Pembelajaran Matematika
}

\author{
Indah Fitria Rahma ${ }^{1}$, Nurlina Ariani Hrp ${ }^{2}$ \\ Universitas Labuhanbatu, Sumatera Utara, Indonesia ${ }^{12}$ \\ e-mail : indahfitria286@gmail.com ${ }^{1}$, nurlinaariani561@ gmail.com ${ }^{2}$
}

\begin{abstract}
Abstrak
Tujuan penelitian adalah untuk mengetahui (1) Perbedaan tingkat kemampuan siswa dalam memahami materi persamaan linier dengan menggunakan pembelajaran kooperatif tipe STAD dan Problem Possing, (2) Hasil belajar kooperatif tipe STAD dan Problem Possing. Populasi dalam penelitian ini adalah siswa kelas X SMA Negeri 1 Rantau Utara yang berjumlah 418 siswa dengan sampel 2 kelas dengan masing-masing berjumlah 35 orang. Jenis penelitian ini adalah penelitian eksperimen semu dengan pendekatan penelitian kuantitatif. Hasil analisis data dari penelitian diperoleh nilai rata-rata hasil belajar siswa dengan menggunakan model pembelajaran kooperatif tipe STAD adalah 13,97 dan simpangan baku $S^{1}=1,98$. Nilai rata-rata hasil belajar, siswa dengan pembelajaran menggunakan tipe problem possing adalah 11,80 dan simpangan baku $S^{1}=1,53$. Oleh karena itu terdapat perbedaan antara hasil belajar siswa yang menggunakan model pembelajaran kooperatif tipe STAD pada kompetensi dasar mendeskripsikan sistem persamaan linier di kelas X SMA Negeri 1 Rantau Utara dengan $a=0,05$ diperoleh $t_{\text {hitung }}=5,13$ dan $t_{\text {tabel }}=1,660$, dengan demikian dapat disimpulkan terdapat perbedaan yang signifikan yang menggunakan model pembelajaran kooperatif tipe STAD dengan menggunakan tipe problem possing. Kesimpulannya bahwa model pembelajaran kooperatif tipe STAD lebih baik dari pada tipe problem possing.
\end{abstract}

Kata Kunci: Problem Possing, Kooperaif Tipe STAD, Sistem Persamaan Linier

\begin{abstract}
The purpose of this study was to determine (1) the difference in the level of students' ability to understand linear equation material using STAD type cooperative learning and Problem Possing, (2) STAD type cooperative learning outcomes and Problem Possing. The population in this study was class X students of SMA Negeri 1 Rantau Utara, totaling 418 students with a sample of 2 classes each with 35 people. This type of research is quasi-experimental research with quantitative research approaches. The results of data analysis from the study obtained the average value of student learning outcomes using the STAD type cooperative learning model is 13.97 and the standard deviation $\mathrm{S}^{1}=1.98$. The average value of learning outcomes, students with learning using the type of problem possing is 11.80 and the standard deviation $S^{1}=1.53$. Therefore there is a difference between student learning outcomes using the STAD type of cooperative learning model on basic competencies describing the system of linear equations in class X of SMA Negeri 1 Rantau Utara with $a=0.05$, obtained tcount $=5.13$ and ttable $=1.660$, thus it can be concluded that there is a significant difference using the STAD type of cooperative learning model using the type of problem possing. The conclusion is that the STAD cooperative learning model is better than the problem possing type.
\end{abstract}

Keywords: Possing Problem, STAD Type Cooperaive, Linear Equation System

Copyright (c) 2020 Indah Fitria Rahma, Nurlina Ariani Hrp

$\square$ Corresponding author :

Address : Jalan SM. Raja No 126 A, Aek Tapa, Rantauprapat

Email : indahfitria286@gmail.com

ISSN 2656-8071 (Media Cetak)

Phone : 081362067516

ISSN 2656-8063 (Media Online) 


\section{PENDAHULUAN}

Pendidikan memegang peranan yang sangat penting dalam pembangunan Negara. Keberhasilan pembangunan disektor pendidikan mempunyai pengaruh yang sangat luas terhadap pembangunan disektor lainnya. Pendidikan yang diselenggarakan dengan baik dan bermutu akan menghasilkan manusia-manusia yang tangguh bagi pembangunan nasional. Hal ini berdasarkan GBPP kurikulum pendidikan dasar dan menengah (Depdikbud, 2008:2).

Namun sampai saat ini mutu dunia pendidikan nasional kita masih memprihatinkan. Sebagaimana yang dikemukakan Abdul Majid (2013) bahwa : "Salah satu permasalahan esensial pendidikan sampai saat ini masih dihadapi bangsa indonesia adalah rendahnya mutu pendidikan sampai saat ini masih dihadapi bangsa indonesia adalah rendahnya mutu pendidikan pada setiap jenis, jenjang, jalur, dan satuan pendidikan.

Berdasarkan uraian diatas, maka dapat dikatakan bahwa peningkatan pendidikan matematika di sekolah terutama terhadap hasil belajar siswa, tidak terlepas dari proses pembelajaran di kelas yang melibatkan interaksi antara guru dengan siswa. Guru hendaknya memilih metode yang tepat untuk digunakan dalam menyampaikan materi pembelajaran. Tetapi dalam proses pembelajaran masih sering ditemui adanya kecenderungan meminimalkan keterlibatan siswa. Dominasi guru dalam proses pembelajaran menyebabkan kecenderungan siswa lebih bersifat pasif sehingga mereka lebih banyak menunggu sajian guru dari pada mencari dan menemukan sendiri pengetahuannya.

Dalam pembelajaran kooperatif, terdapat empat pendekatan yang seharusnya merupakan bagian dari kumpulan strategi guru pemula yang dikemukakan oleh Soetomo (2003 :144), yaitu Student Teams Achievement Division (STAD), Jigsaw, Investigasi Kelompok (IK), dan Pendekatan Struktual. Tetapi dalam penelitian ini peneliti hanya menggunakan "Model Pembelajaran kooperatif Tipe STAD". Dalam pembelajaran kooperatif tipe STAD, tim-tim saling heterogen membantu satu sama lain, belajar dengan menggunakan berbagai metode pembelajaran kooperatif.

Adapun sebab mengapa peneliti menggunakan pembelajaran kooperatif tipe STAD, hal ini dikarenakan bahwa dalam penerapan pembelajaran kooperatif tipe STAD diterapkan atas dasar teori bahwa siswa akan lebih mudah menemukan dan memahami konsepkonsep itu dengan temannnya (Slavin, 2005:82). Pembelajaran kooperatiftipe STAD menekankan aktivitas dimana siswa belajar dalam kelompk untuk mempelajari materi dan mengerjakan tugas untuk mencapai tujuan yang sama.

Salah satu alasan mengapa para ahli psikolog perilaku menjadi tertarik dalam pengolahan diri sendiri adalah teramatinya kecenderungan bahwa siswa yang diajari dengan metode prilaku klasik jarang menggeneralisasikan pembelajaran mereka ke situasi yang baru. Pembelajaran dengan kooperatif lebih menguntungkan bagi siswa dalam menyelesaikan permasalahan persamaan, sebab pembelajaran kooperatif manuntun kerjasama siswa dan saling ketergantungan dalam struktur tugas, tujuan, dan hadiah. Siswa yang bekerja sama pada suatu tugas bersama, dan mereka harus mengkoordinasi usahanya untuk menyelesaikan tugasnya, agar dapat mencapai tujuan tertentu. Agar siswa dapat mencapai sasaran yang dipersyaratkan maka model-model pembelajaran matematika juga sangat diperlukan.

Pembelajaran kooperatif tipe STAD dengan bantuan pengajuan masalah digunakan atas dasar agar lebih melibatkan siswa lebih berpartisipasi dalam proses belajar, dan diharapkan dengan metode ini dapat membantu siswa mencari himpunan penyelesaian pada persamaan dan menggunakan berbagai rumus. Oleh karena itu, dengan cara pembelajaran pengajuan masalah dari siswa, maka hal tersebut memungkinkan siswa teelibat lebih besar dalam kegiatan mental melalui pengajuan masalah, tukar pendapat, membaca sendiri dan mencoba sendiri, agar siswa lebih kreatif dan hasilnya akan lebih permanen bagi diri 
213 Metode Kooperatif Tipe STAD dan Problem Posing dalam Pembelajaran Matematika- Indah Fitria Rahma, Nurlina Ariani Hrp

DOI: https://doi.org/10.31004/edukatif.v2i2.140

siswa dibanding dengan ilmu dengan cara mendengar serta mengikut apa yang dikatakan oleh guru.

\section{METODE PENELITIAN}

Penelitian ini dilaksanakan di SMA Negeri 1 Rantau Utara Jalan Mahoni Rantauprapat Kabupaten Labuhanbatu. Populasi dalam penelitian ini adalah siswa kelas X. Dimana kelas tersebut dipilih secara acak dari pada kelas yang ada sebanyak 10 kelas yang berjumlah 418 siswa. Pengambilan sampel penelitian ini adalah menggunakan purposive random sampling

Purposive random sampling yaitu pemilihan sampel berdasarkan alasan tujuan tertentu atau secara acak. Kemudian memilih 2 kelas dari 10 kelas paralel yang ada, diperoleh sebagai kelas eksperimen yakni X-A (menggunakan model pembelajaran kooperatif tipe STAD) dan kelas kontrol yakni X-C (menggunakan model Problem Possing) yang masing-masing berjumlah 35 orang. Jenis penelitian ini adalah penelitian eksperimen. Pendekatan yang digunakan adalah pendekatan kuantitatif yang bertujuan untuk memaparkan proses dan hasil penggunaan kooperatif STAD dan Problem Possing dalam pembelajaran matematika dalam upaya meningkatkan hasil belajar siswa tentang konsep persamaan guna memperoleh hasil belajar sesuaia denan yang diharapkan. Instrumen yang digunakan sebagai pengumpulan data adalah test mengenai pokok bahasan sistem persamaan linier dalam bentuk pilihan ganda yang berjumlah 20 soal. Untuk memperoleh validitas tes dan realibilitas tes serta daya beda soal dan tingkat kesukaran soal terlebih dahulu dilakukan pengujian tes. Dalam penelitian ini hipotesis penelitian dianalisis dengan t-test. Analisis t-test adalah analisis yang digunakan untuk membandingkan dua variabel yang sifatnya bebas satu sama lain. 


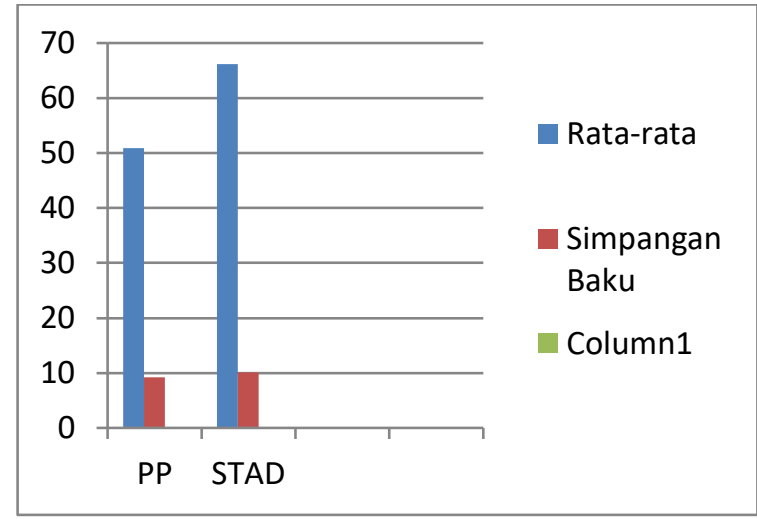

Diagram 1. Rata-Rata dan Simpangan Baku Hasil Belajar

Hal tersebut dapat terjadi karena model pembelajaran kooperatif tipe Problem Possing memanfaatkan siswa lebih banyak belajar sendiri atau dalam bentuk kelompok, mengembangkan kekreatifan dalam pemecahan suatu masalah. Dalam metode ini siswa benar-benar ditempatkan sebagai objek belajar. Peranan guru dalam model pembelajaran kooperatif tipe Problem Possing hanya sebagai pembimbing dan fasilitator belajar. Sedangkan pada tipe problem possing siswa lebih banyak tergantung pada guru sebagai pemberi informasi dalam kegiatan belajar siswa kurang optimal, karena guru mendominasi kegiatan belajar mengajar.

\section{KESIMPULAN}

Dari hasil pengujian hipotesis yang diajukan dapat diterima yaitu terdapat perbedaan pada hasil belajar siswa yang menggunakan tipe STAD dan tipe problem possing pada materi persamaan linier kelas X SMA Negeri 1 Rantau Utara. Hal tersebut dapat terjadi karena model pembelajaran kooperatif tipe STAD memanfaatkan siswa lebih banyak belajar sendiri atau dalam bentuk kelompok, mengembangkan kekreatifan dalam pemecahan suatu masalah. Dalam metode ini siswa benar-benar ditempatkan sebagai objek belajar. Peranan guru dalam model pembelajaran kooperatif tipe STAD hanya sebagai pembimbing dan fasilitator belajar. Sedangkan pada tipe problem possing siswa lebih banyak tergantung pada guru sebagai pemberi informasi dalam kegiatan belajar siswa kurang optimal, karena guru mendominasi kegiatan belajar mengajar.

\section{DAFTAR PUSTAKA}

Abdul Majid. (2013). Strategi Pembelajaran. Bandung : PT Remaja Rosdakarya.

Abdurrahman, Mulyono. 2003. Pendidikan Bagi Anak Berkesulitan Belajar. Jakarta: Rineka Cipta.

Depdikbud. 2008. Kamus Besar Bahasa Indonesia. Jakarta: Balai Pustaka.

Slavin, Robert E, 2005. Cooperative Learning: Teori, Riset dan Praktik,. Bandung: Nusa Media.

Subryanto, Muhammad. 2014. Implementasi Pendekatan Pembelajaran Matematika Realistik (PMR) untuk Meningkatkan Pemahaman Siswa terhadap Soal Cerita tentang Himpunan. Jurnal Pendidikan matematika Volume 3 Nomor 2. 12 April 2017. 